Spinhoven, P., Kuile, M. ter, Kole-Snijders, A.M.J., Hutten Mansfeld, M., Ouden, D.J. den, Vlaeyen, J.W.S.

Catastrophizing and internal pain control as mediators of outcome in the multidisciplinary treatment of chronic low back pain.

European Journal of Pain: 8, 2004, p. 211-219

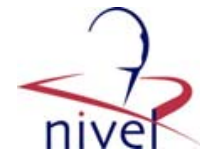

\begin{tabular}{|c|c|}
\hline Postprint Version & 1.0 \\
\hline Journal website & http://www.sciencedirect.com/science/journal/10903801 \\
\hline Pubmed link & $\begin{array}{l}\mathrm{http}: / / \text { www.ncbi.nlm.nih.gov/entrez/query.fcgi?cmd=Retrieve\&db=pubmed\&dop } \\
\text { t=Abstract\&list uids=15109971\&query hl=10\&itool=pubmed docsum }\end{array}$ \\
\hline DOI & 10.1016/j.ejpain.2003.08.003 \\
\hline
\end{tabular}

\title{
Catastrophizing and internal pain control as mediators of outcome in the multidisciplinary treatment of chronic low back pain
}

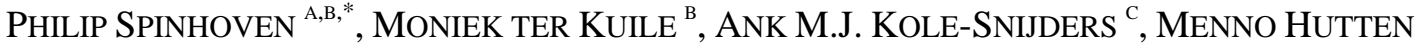 \\ MANSFELD ${ }^{\mathrm{A}}$, DIRK-JAN DEN OUDEN ${ }^{\mathrm{A}}$, JOHAN W.S. VLAEYEN ${ }^{\mathrm{D}, \mathrm{E}}$ \\ ${ }^{a}$ Faculty of Social and Behavioral Sciences, Department of Clinical and Health Psychology, Leiden \\ University, P.O. Box 9555, 2300 RB Leiden, The Netherlands \\ ${ }^{\mathrm{b}}$ Leiden University Medical Center, Leiden, The Netherlands \\ ${ }^{\mathrm{c}}$ Hoensbroeck Rehabilitation Center, The Netherlands \\ ${ }^{\mathrm{d}}$ Maastricht University, Maastricht, The Netherlands \\ ${ }^{\mathrm{e}}$ University Hospital of Maastricht, Maastricht, The Netherlands \\ * Corresponding author. Tel.: +31-71-5273377; fax: +31-71-5274678. E-mail address: \\ Spinhoven@fsw.leidenuniv.nl (P. Spinhoven)
}

\begin{abstract}
The aim of the present study was to examine (a) whether a cognitive-behavioral treatment (differentially) affects pain coping and cognition; and (b) whether changes in pain coping and cognition during treatment mediate treatment outcome. Participants in this randomized clinical trial were 148 patients with chronic low back pain attending a multidisciplinary treatment program consisting of operant-behavioral treatment plus cognitive coping skills training $(N=59)$ or group discussion $(N=58)$ or allocated to a waiting list control condition $(N=31)$. Patients improved with respect to level of depression, pain behavior and activity tolerance at posttreatment and 12-month follow-up. Treatment also resulted in a short- and long-term decrease in catastrophizing and an enhancement of internal pain control. Changes in catastrophizing and to a lesser degree in internal pain control mediated the reduction in level of depression and pain behavior following treatment. The use of behavioral and cognitive interventions aimed at decreasing catastrophizing thoughts about the consequences of pain and promoting internal expectations of pain control possibly constitute an important avenue of change irrespective of the type of treatment.
\end{abstract}

\section{INTRODUCTION}

Among persons with chronic pain, major differences in emotional and behavioral adjustment are found. On the basis of models of stress and coping (Lazarus and Folkman, 1984), a possible role for pain beliefs and coping strategies in adjustment to pain has been proposed. Beliefs can be defined as stable thoughts patients have regarding their pain problem. Two important types of beliefs can be discriminated: attributions and expectancies. Attributions concern interpretations of the pain in terms of relevance and potential danger. Expectancies are thoughts with respect to the anticipated consequences, such as thoughts about one's ability to control pain and the effectiveness of these coping efforts. Attributions and expectancies are hypothesized to have a direct but also an indirect 
Spinhoven, P., Kuile, M. ter, Kole-Snijders, A.M.J., Hutten Mansfeld, M., Ouden, D.J. den, Vlaeyen, J.W.S.

Catastrophizing and internal pain control as mediators of outcome in the multidisciplinary treatment of chronic low back pain.

European Journal of Pain: 8, 2004, p. 211-219

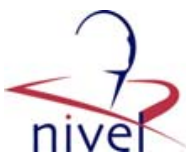

effect on adjustment through their impact upon coping efforts. Pain coping can be defined as purposeful cognitive or behavioral efforts to manage or vitiate the negative impact of pain. In a classification scheme as proposed by Fernandez (1986) cognitive coping strategies are grouped into three broad categories: imagery, selfstatement and attention-diversion. Available evidence suggests that especially attributions such as catastrophizing and expectancies such as perceived control over pain mediate some of the relationships between pain and adjustment (Jensen et al., 1991).

Most multidisciplinary pain treatment programs are based on cognitive-behavioral models of pain, in which cognitions with respect to pain and responses to cope with pain are assumed to play a crucial role in pain control and emotional and behavioral adjustment to pain (Turner and Chapman, 1982). In programs based on these theoretical models, many treatment components are explicitly focused on modifying cognitive and behavioral responses to pain with the purpose of improving physical, emotional and behavioral functioning. Given these assumptions and therapeutic strategies, it is remarkable that relatively many studies have tried to evaluate the effectiveness of these programs (Morley et al., 1999), but only a few studies have tested the hypothesized relationship of pain beliefs and coping responses with outcome following multidisciplinary pain treatment.

In two previous studies (Jensen et al., 1994, 2001) it was found that changes in pain beliefs and coping strategies were associated with improvement in patients who followed a multidisciplinary pain program. More specifically, it was found that increasing the belief in control over pain and decreasing the endorsement of other cognitions and coping responses (such as catastrophizing or resting) may be adaptive. Limitations of these studies included among others: (a) because of the uncontrolled nature of these studies it remains undecided whether changes in pain beliefs and coping strategies were the direct result of treatment; (b) the correlational nature of the data does not allow conclusions regarding sequential or causal relationships between process and outcome variables.

The purpose of the present study was to further explore the relationships among changes in pain beliefs and coping responses and outcome in pain patients participating in a multidisciplinary pain program. It was tried to improve the methodology of previous studies by (a) the inclusion of a notreatment control condition; (b) the inclusion of different forms of active treatment; and (c) testing whether in particular changes in pain cognitions and cognitive pain coping strategies during treatment mediate the relationship of treatment with outcome.

The present study constitutes a re-analysis of the results of a Dutch randomized controlled clinical trial of the supplemental value of cognitive copings skills training as an adjunct to operant-behavioral treatment in chronic low back pain patients (Kole-Snijders et al., 1999). In the original statistical analysis of the results of this clinical trial, a variable reduction procedure consisting of two consecutive principal-components analyses was performed. In this way the number of process and outcome variables was greatly reduced. However, because both process and outcome variables were included in the same variable reduction procedure the results do not allow for differentiation between the change of process variables and the outcome obtained. Neither was it possible to examine the possible relationships between both groups of variables. Because, the design of this particular clinical study was very suitable to answer the questions mentioned above, the study results of the trial were reanalyzed for this specific purpose.

To summarize, the aim of the present study was twofold:

a) to investigate whether treatment (differentially) affects pain cognitions and cognitive pain coping strategies;

b) to investigate whether changes in pain coping and pain cognitions during treatment mediate the outcome of treatment.

It was hypothesized that treatment will result in a greater enhancement of perceived pain control and greater reduction of catastrophizing and external pain control than no-treatment and also that the combination of a cognitive coping skills training with an operant- behavioral treatment will be more effective than operant-behavioral treatment alone on measures for cognitive pain coping strategies. Moreover, it was hypothesized that changes in pain and adjustment to pain will be mediated by decatastrophizing pain and a enhanced perceived internal control of pain. 
Spinhoven, P., Kuile, M. ter, Kole-Snijders, A.M.J., Hutten Mansfeld, M., Ouden, D.J. den, Vlaeyen, J.W.S.

Catastrophizing and internal pain control as mediators of outcome in the multidisciplinary treatment of chronic low back pain.

European Journal of Pain: 8, 2004, p. 211-219

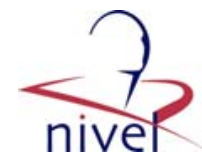

\section{SUBJECTS AND METHODS}

The methods of the present study are extensively described elsewhere (Kole-Snijders et al., 1999) and here only a short description of participants, measures, treatments, and study design is presented with special emphasis on the process variables under study.

\subsection{Subjects}

Subjects were referred to the "Hoensbroeck" Rehabilitation Center by their general practitioner or by a medical specialist. The main inclusion criteria for the study were: low-back pain for at least 6 months, age between 18 and 65 years, a discrepancy between objective findings and pain complaints and cooperation of the spouse to participate in a weekly spouse training program. The main exclusion criteria were: illiteracy, pregnancy, involvement in litigation concerning social disability income, alcohol or drug abuse, serious psychopathology (e.g., antisocial personality disorder, psychosis, or organic brain damage; patients with major depression were not excluded) and specific medical disorders requiring medical treatment or rendering patients unable to participate in the program.

From the 237 chronic low back pain (CLBP) patients who were referred to the study, 62 (26\%) did not meet these criteria. The most important reason for not entering the study was severe psychopathology (44\%) as evidenced by elevated scores on all scales of the MMPI (Hathaway and McKinley, 1967), except Hypochondriasis, Hysteria, Masculinity-Femininity, and Hypomania in comparison to patients who started the study.

Of the 148 patients with who eventually started the measurements, results were available for 130 patients at posttreatment (88\%) and of the 102 patients who had received active treatment 12-month follow-up data were available for 89 patients (87\%). No significant differences with respect to biographical, medical status and outcome variables between patients who dropped out or finished treatment were observed. However, with respect to pretreatment scores on the Pain Coping and Cognition List (PCCL) (see below) patients who dropped out had significantly lower scores for Catastrophizing than treatment completers. Posttreatment outcome and process measurements of patients with complete and missing 12-month follow-up data did not show significant differences.

The sample of 148 patients who entered the study (54 men and 94 women) had a mean age of 39.8 years $(S D=9.1$, range $=18-64)$. They constituted a group of moderately to severely disabled CLBP patients. The mean pain duration was 9.8 years $(\mathrm{SD}=8.7$, range 10 months-40 years). Most patients did not have more than 10 years of education (78\%). Of the total sample, $80 \%$ was married or cohabitating and $79 \%$ received financial disability compensation, with a mean duration of 3.7 years. Before entering the program, $39 \%$ had received back surgery and $28 \%$ used supportive equipment for ambulation.

\subsection{Measures}

\subsubsection{Outcome variables}

The following self-report and observational outcome measures for pain and emotional and behavioral adjustment to pain were selected for the purpose of the present study. Pain intensity. The Pain Rating Index (PRI) of the McGill Pain Questionnaire of Melzack (1975) was used. Pain Behavior. A research assistant, who was unaware of the allocation of patients to conditions, completed the Pain Behavior Scale (PBS) (Richards et al., 1982). The PBS is a reliable and valid measure of eight different overt pain behaviors (e.g. talking about pain, distorted mobility, use of supportive equipment). Depression. Patients completed the original 21-item version of the Beck Depression Inventory (BDI) (Beck et al., 1979). Activity tolerance. Patients completed the Behavioral Approach Tests (BAT: Kole-Snijders et al., 1990) during which patients are asked to (a) walk and (b) ride a bicycle and stop if pain prevented them from continuing, up to a preset maximum time of 7 and 14 min, respectively. Given the high intercorrelations between the walking distance and walking and bicycling time (range of correlations 0.58-0.88), a composite BAT score was calculated by summing up the three BAT subscale scores after transformation into standard $z$-scores.

\subsection{Process variables}

Recently, the Pain Coping and Cognition List (PCCL) (Stomp-van den Berg et al., 2001) has been developed on the basis of the following three already existing Dutch questionnaires: the Pain 
Spinhoven, P., Kuile, M. ter, Kole-Snijders, A.M.J., Hutten Mansfeld, M., Ouden, D.J. den, Vlaeyen, J.W.S.

Catastrophizing and internal pain control as mediators of outcome in the multidisciplinary treatment of chronic low back pain.

European Journal of Pain: 8, 2004, p. 211-219

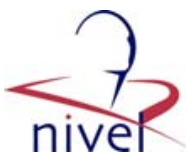

Cognition List (PCL; Vlaeyen et al., 1990) consisting of 5 subscales, the Dutch version of the Coping Strategies Questionnaire (CSQ; Rosenstiel and Keefe, 1983; Spinhoven et al., 1994) consisting of seven subscales and the Dutch version of the Multidimensional Pain Locus of Control Questionnaire (MPLC; Engstrom, 1983; ter Kuile et al., 1993) consisting of three subscales. By developing the PCCL redundancy between the above mentioned 15 subscales was eliminated, while the unique contribution of the different scales was preserved. The PCCL aims to measure cognitions related to pain in a comprehensive way and covers attributions, expectancies as well as cognitive coping strategies.

The PCCL is a 42-item self-report questionnaire with a six-point Likert-scale with answering categories ranging from 'totally disagree' to 'totally agree'. The scale consists of the following four factor-analytically derived subscales: (a) Catastrophizing (i.e. negative thoughts about the catastrophical consequences of pain (e.g. "Because of the pain I do not feel myself like a complete human being')) (12 items); (b) Pain Coping (i.e. primarily cognitive strategies to cope with pain such as diverting attention, ignoring pain or using coping self-statements (e.g. "When I have pain, I pretend the pain is not there'”)) (11 items); (c) Internal Pain Control (i.e. positive expectancies about personal control over pain (e.g. "I think that I can influence my pain positively")) (11 items); (d) External Pain Control (i.e. positive expectancies about control over pain by medical specialists or other significant others (e.g. "Only doctors can help me with my pain”)) (8 items). The internal consistencies of the subscales proved to be good: alpha Catastrophizing 0.85; Pain Coping 0.84; Internal Pain Control 0.78; and External Pain Control 0.81. Also, test-retest correlation coefficients after an interval of 2 weeks were satisfactory: Catastrophizing 0.75; Pain Coping 0.64; Internal Pain Control 0.69; and External Pain Control 0.79. Moreover, the construct validity of the subscales was satisfactory (see Stomp-van den Berg et al. (2001) for more details on the psychometric properties of the PCCL). Because in the clinical trial of Kole-Snijders et al. (1999) all three the questionnaires on which the PCCL is based were used (i.e. the PCL, CSQ and MPLC), it was possible to reconstruct the PCCL on the basis of these questionnaires for the purpose of the present secondary analyses. In this way the amount of cognitive variables could be reduced from 15 to four while preserving the unique contribution of the different scales. Since the answering formats of the CSQ and MPLC items were somewhat different from the 6-point Likert scales of the PCL and PCCL items, a transformation of CSQ and MPLC scale scores was performed in order to obtain an uniform 6-point Likert scale.

\subsection{Study design}

Patients were allocated at random to: (1) an operantbehavioral treatment + cognitive coping skills treatment (OPCO); (2) an operant-behavioral treatment + group discussion (OPDI);or (3) a waiting list control condition (WLC). The waiting list period was 10 weeks, a timeperiod comparable to the duration of the active treatments OPCO and OPDI. After the waiting list period, the patients from the WLC received operant-behavioral treatment as usual and were excluded from further analyses in the present study. All the patients were assessed at pretreatment 1 and pretreatment 2 (with a two-week interval), after 4 weeks of treatment, and at posttreatment after 10 weeks of treatment. For this study the mean data of the pretreatment assessments 1 and 2 and posttreatment measurements after 10 weeks were used. Furthermore, patients who received OPCO or OPDI were measured at 6-month and 12month follow- up. For this study the 12-month follow-up data were selected for further statistical analysis in order to obtain data about the longest follow-up period as possible.

\subsection{Treatments}

During the first 2 weeks of treatment, baseline levels of activities and pain behaviors were registered. This was followed by 5 weeks of inpatient treatment and 3 weeks of outpatient treatment 3 days a week. All patients received operant-behavioral treatment aimed at increasing healthy behaviors and decreasing pain behaviors. On the basis of the baseline registration, a treatment contract was made with the patient in which concrete goals and quota were written down. The patient agreed to follow the quota according to the activity- rest contingency principle. Treatment was provided by the entire rehabilitation team using a manualized treatment protocol. This part of the treatment consisted of minimally $132 \mathrm{~h}$ of therapy contact of the patient with physical therapists, occupational therapists, psychologists or the rehabilitation team. Moreover, the operantbehavioral treatment included a 
Spinhoven, P., Kuile, M. ter, Kole-Snijders, A.M.J., Hutten Mansfeld, M., Ouden, D.J. den, Vlaeyen, J.W.S.

Catastrophizing and internal pain control as mediators of outcome in the multidisciplinary treatment of chronic low back pain.

European Journal of Pain: 8, 2004, p. 211-219

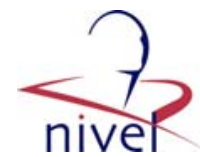

structured spouse training program of 7 weekly sessions of $90 \mathrm{~min}$. Spouses were explained the operant model of pain and were thought to differentiate between pain and healthy behaviors, to identify their own responses to these behaviors, and to socially reinforce healthy behaviors.

In addition, patients randomly selected for the OPCO condition received a supplemental cognitive coping skills training aimed at increasing pain control and self-efficacy expectations. The treatment was given according to a manual and consisted of three phases: a reconceptualization phase, a skills acquisition phase, and a generalization phase. The reconceptualization phase aimed at enhancing selfcontrol and resourcefulness by stressing that hurt does not necessarily mean harm and that pain is influenced by multiple factors. In the skills acquisition phase patients learned techniques aimed at imaginative transformation of the pain sensation, pain-incompatible sensory imagery and applied relaxation. After this a generalization phase followed during which patients were given homework assignments to practice imagery and relaxation exercises with the aid of audiotapes. The other patients randomly selected for the OPDI condition attended a group discussion program to provide an attention control condition for the cognitive treatment. In this program psycho-education about pain, listening to various audio-taped music fragments and group discussions were the main therapy ingredients. Both the cognitive treatment and the group discussion program consisted of 12 group sessions of 90 min in combination with homework assignments.

\subsection{Compliance and treatment integrity checks}

To measure patients' compliance, the written homework assignments from the cognitive coping skills training and group discussion were checked. For OPCO, the number of times that the patients filled out their pulse rate before and after a relaxation exercise was counted as well as the number of times they described the results of an imagery exercise. For OPDI, the number of times patients wrote comments about the music they had listened to and about the texts they had read was counted.

Audiotapes of several sessions of both programs (OPCO and OPDI) were made according to a preset schedule. Ten fragments of 5 min each, taken from different sessions in both programs were randomly selected and presented to nine behavior therapists who worked at different mental health treatment centers. After listening to each fragment, therapists were asked to determine whether the fragment belonged to the pain coping skills training or to the group discussion program.

\subsection{Statistical analysis}

In order to investigate whether treatment (differentially) affects pain cognitions and cognitive pain coping strategies, split-plot analyses of variance with one between subjects-variable (Group: WLC, OPCO, OPDI) and one within-subjects variable (Time: Pretreatment, Posttreatment) were conducted. After exclusion of the patients in the WLC, similar analyses of variance were executed to identify process and outcome measures that changed from pretreatment, to posttreatment and to 12- month follow-up.

To investigate whether changes in pain coping and pain cognitions during treatment mediate the outcome of treatment, first residualized gain scores were calculated by removing from the posttreatment, and hence from the gain, the portion that could have been predicted linearly from the pretreatment scores by use of hierarchical regression analysis. Secondly, following the three-step process for assessing mediation as described by Baron and Kenny (1986), it was analyzed whether changes on the PCCL during treatment mediate treatment outcome. The statistical significance of differences in the magnitude of correlations was analyzed by calculating $95 \%$ confidence intervals.

\section{RESULTS}

\subsection{Compliance and treatment integrity}

The patients did not have as much practice during the program as planned. For OPCO, patients completed on average $63 \%$ of the relaxation exercises and about $75 \%$ of the imagery exercises. For OPDI, patients completed an average of $66 \%$ of the homework assignments for music and about half of the assignments for the texts.

The interrater agreement between the nine independent behavior therapists was acceptable $(k=0.60)$, suggesting that the raters agreed highly on their judgment about the origin of the treatment fragments. 
Spinhoven, P., Kuile, M. ter, Kole-Snijders, A.M.J., Hutten Mansfeld, M., Ouden, D.J. den, Vlaeyen, J.W.S.

Catastrophizing and internal pain control as mediators of outcome in the multidisciplinary treatment of chronic low back pain.

European Journal of Pain: 8, 2004, p. 211-219

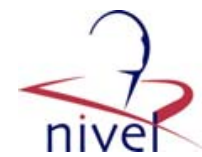

Of a total of 10 fragments to be classified by nine raters (10 per rater), only 16 fragments were assigned to the wrong condition (18\%).

\subsection{Treatment effects on process and outcome variables}

\subsubsection{Process variables}

Three (Group: WLC, OPCO, OPDI) by 2 (Time: Pretreatment, Posttreatment) split-plot analyses of variance of the PCCL subscale scores revealed significant Time effects and significant Group X Time interaction effects with respect to scores for Catastrophizing $(F(1,124)=59.96, p<0.001 ; F(2,124)=$ $6.70, p<.01)$, Internal Pain Control $(F(1,126)=46.79, p<0.001 ; F(2,126)=9.88, p<0.001)$ and External Pain Control $(F(1,126)=14.26, p<0.001 ; F(2,126)=-5.97, p<0.01)$, but not for Pain Coping $(F(1,126)=1.45$, n.s.; $F(2,126)=1.22$, n.s. $)$. In none of the analyses of PCCL subscale scores, a significant main effect for Group was found. Post hoc analyses with Bonferroni multiple comparisons revealed that in comparison to a waiting list control condition active treatment significantly increased scores for Internal Pain Control and significantly decreased scores for Catastrophizing and External Pain Control, while no significant differences between active treatment conditions were observed.

Two (Group: OPCO, OPDI) by 3 (Time: Pretreatment, Posttreatment and 12-month Follow-up) splitplot analyses of variance of the PCCL subscale scores showed significant Time effects with respect to scores for Catastrophizing $(F(2,84)=48.00, p<0.001)$, Internal Pain Control $(F(2,84)=$ $36.44, p<0.001)$, External Pain Control $(F(2,86)=10.62, p<0.001)$ and Pain Coping $(F(2,85)=$ $3.42, p<0.05)$. In none of the analyses of PCCL subscale scores significant Group effects or significant Group X Time interaction effects were observed. Bonferroni multiple comparisons revealed that the significant increase of scores for Internal Pain Control and significant decrease of scores for Catastrophizing during the treatment phase was preserved during the 12-month follow-up period, but that the difference between pretreatment and 12-month followup scores for External Pain Control was no longer significant, while in the group of patients who completed their follow-up assessment scores for Pain Coping at posttreatment proved to be significantly higher than at pretreatment. Table 1 summarizes the changes on the PCCL between conditions.

\section{[ TABLE 1 ]}

\subsubsection{Outcome variables}

Because no differential treatment effects on PCCL scores were found, for the purpose of clarity of exposition it was decided to collapse data across treatment conditions in the further statistical analyses. Also in the original publication on the present randomized controlled trial (Kole-Snijders et al., 1999) the supplemental value of the cognitive coping skills training was almost absent.

Two (Group: Treatment, WLC) by 2 (Time: Pretreatment, Posttreatment) split-plot analyses of variance of scores on the outcome measures showed significant Group X Time interaction effects with respect to scores on the Pain Behavior Scale $(F(1,125)=12.94, p<0.001)$, Behavioral Approach Test $(F(1,123)=34.74, p<0.001)$, and Beck Depression Inventory $(F(1,114)=4.54, p<0.05)$, as well as significant main effects for Time with respect to scores on the Pain Behavior Scale $(F(1,125)=48.52$, $p<0.001)$ and Behavioral Approach Test $(F(1,123)=26.60, p<0.001)$. In none of the analyses a significant main effect for Group was found. Moreover, no significant main or interaction effects for Pain Rating Index scores were observed. Multiple Bonferroni comparisons of the posttreatment scores showed a significantly greater reduction of scores for pain behavior and level of depression and a significantly greater increase of scores for activity tolerance after treatment in comparison to the waiting list condition.

Results of subsequent repeated measures analyses of variance indicated that at 12-month follow-up essentially the same results were found with significant main effects for Time with respect to PBS $(F(2,84)=47.07, p<0.001)$, BAT $(F(2,79)=54.92, p<0.001)$ and BDI scores $(F(2,72)=4.47, p<$ 
Spinhoven, P., Kuile, M. ter, Kole-Snijders, A.M.J., Hutten Mansfeld, M., Ouden, D.J. den, Vlaeyen, J.W.S.

Catastrophizing and internal pain control as mediators of outcome in the multidisciplinary treatment of chronic low back pain.

European Journal of Pain: 8, 2004, p. 211-219

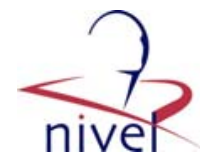

$0.05)$, but not with respect to PRI-scores $(F(2,82)=2.84$, ns). Multiple Bonferroni comparisons indicated that significant treatment gains at posttreatment were retained at 12-month follow-up.

Table 2 summarizes the changes in outcome measures between conditions.

\section{[ TABLE 2 ]}

\subsubsection{Changes in pain coping and cognitions as predictors of treatment outcome}

Baron and Kenny (1986) describe a three-step process for determining mediation. In the first step, the mediator (changes in pain cognition) is regressed on the predictor (treatment). In the second step, the criterion (outcome) is also regressed on the predictor (treatment). In the third step, the criterion (outcome) is regressed on both the predictor (treatment) and the mediator (change in pain cognition). In the present case, mediation would be suggested if (a) treatment is significantly related to changes in pain cognition, (b) outcome is significantly related to treatment, and (c) the relationship between treatment and outcome decreases (or goes to zero) when changes in pain cognition is entered into the equation.

Table 3 shows zero-order correlations between treatment coded as a dummy variable (active treatment $=0$ and waiting list $=1$ ), residualized gain scores on the four subscales of the PCCL, and residualized gain scores on the PBS, BAT, BDI and MPQ. Baron and Kenny's (1986) steps 1 and 2 are confirmed by the significant zero-order correlation of most of the variables in Table 3. Next, several multiple regression analyses were performed with residualized gain scores for PBS, BAT, BDI and MPQ as the dependent variable and treatment and residualized gain scores on the four subscales of the PCCL forced into the equation as independent variables.

\section{[ TABLE 3 ]}

Table 4 presents semi-partial correlations between treatment and residualized gain scores for PBS, BAT, BDI and MPQ when changes on the four subscales of the PCCL are controlled for. As can be inferred from Table 4 the semi-partial correlations between treatment on the one hand and changes on the BDI and PBS on the other are significantly smaller than the magnitude of the corresponding zeroorder correlation $(p<0.05)$ and no longer significant suggesting rather strong mediation. Although the magnitude of the semi-partial correlation between treatment and changes on the BAT is also significantly smaller than the magnitude of the zero-order correlation $(p<0.05)$, the correlation remains substantial and significant suggesting only partial mediation. Interestingly, the semi-partial correlation coefficients of Catastrophizing with outcome proved to be significant in all regression models after statistically correcting for the influence of treatment and changes on the other three PCCL subscales, while most of the semi-partial correlation coefficients of Internal and External Pain Control with outcome are no longer significant. The positive association of Pain Coping with the Pain Rating Index of the MPQ becomes significant suggesting that higher levels of pain are accompanied with higher levels of pain coping (such as diverting attention, ignoring pain or using coping selfstatements). These results do not seem to be affected by problems of multicollinearity, since the highest correlation of change scores on PCCL subscales was between Catastrophizing and Internal Pain Control and amounted to $r=-0.45$. To summarize, the mediational analysis suggest that especially changes in Catastrophizing seem to mediate improvement in depression and pain behavior, while changes in activity tolerance are only partly related to changes in pain cognitions.

\section{[ TABLE 4 ]}

\section{DISCUSSION}

Unequivocal evidence for treatment-produced changes in pain cognitions was found. In comparison to a waiting list control condition, Catastrophizing about the consequences of pain and an External Pain Control with positive expectations about the control over pain by medical specialists significantly 
Spinhoven, P., Kuile, M. ter, Kole-Snijders, A.M.J., Hutten Mansfeld, M., Ouden, D.J. den, Vlaeyen, J.W.S.

Catastrophizing and internal pain control as mediators of outcome in the multidisciplinary treatment of chronic low back pain.

European Journal of Pain: 8, 2004, p. 211-219

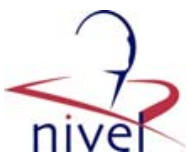

decreased, while Internal Pain Control with positive expectations about personal control over pain significantly increased. However, at 12-month follow-up the decrease in External Pain Control was no longer significant. Remarkably, Pain Coping was not enhanced following treatment, although several coping strategies as measured with this PCCL subscale were targeted in the cognitive coping skills training (i.e. diverting attention, ignoring pain and using coping self-statements). Given the results of our treatment integrity checks, these results do not seem to be due to lack of treatment fidelity. However, patients did not have as much practice during the program as planned. Because regular practice is required to sufficiently achieve pain coping skills a higher compliance to do homework assignments may be necessary to produce differential treatment effects of pain coping and cognition. Moreover, it is conceivable that the discussion group did not constitute a true attention control group because psycho-education about pain was provided, the topics discussed within the group were painrelated and attention-diversion by the use of music was provided. Consequently, it can not be totally excluded that the absence of differential treatment effects on pain cognitions is due to the fact that patients who received group discussion unintentionally received a component of cognitive skills training.

However, the present study results are also consistent with the possibility that nonspecific factors of treatment (such as a clear treatment rationale, a highly structured treatment program, an emphasis on active participation by the patient himself and (self-)reward for therapeutic gains achieved) may be more influential in changing Catastrophizing and Internal Pain Control than the use of particular cognitive-behavioral treatment methods. Almost $90 \%$ of the treatments contacts took place in the context of the operant-behavioral treatment program. An operant-behavioral program may constitute a potent strategy for cognitive restructuring and promote less catastrophizing and more internal pain control by its active emphasis on behavior modification. As has already been stressed by Bandura (1977) behavior modification possibly constitutes the most potent strategy for cognitive restructuring. Correlational data do not allow for inferential conclusions. In other words, the fact that process variables accounted for some of the variance in changes in outcome measures may reflect an epiphenomenon of change in outcome measures as the result of other causative change processes. However, the results of the mediational analysis are not entirely consistent with this possibility. Rather strong evidence for mediation was found meaning that the effect of treatment on level of depression and pain behaviors (such as distorted mobility and verbal and nonverbal complaints) was greatly reduced and no longer significant after controlling for changes in pain cognitions, especially Catastrophizing. On the other hand, the effect of treatment on a measure for more objective limitations (such as activity tolerance) was only partly mediated by changes in pain cognitions. The similarity of our basic findings to results as reported by Jensen et al. $(1994,2001)$ for a heterogeneous group of patients participating in a multidisciplinary pain treatment program suggest that the present study results are not unique for the present sample but may have a wider applicability. Together, these data support the idea that cognitive processes may have some causative status particularly in the process of change of complaints, such as depression and pain behavior. However, the alternative explanation that decreases in depression and pain behavior result in decreases in catastrophizing cognitions and enhanced pain control cannot be ruled out. Future clinical studies using a design in which changes in cognition and outcome are repeatedly measured over the course of treatment are necessary in order to conduct a more fine-grained analysis of the direction of causality or influence.

Although changes with respect to several pain cognitions as tapped by the PCCL were associated with outcome, the impact of Catastrophizing surpassed that of Internal Pain Control. These clinical findings accord with those of various experimental, epidemiological and clinical studies in which it was found that chronic pain patients who catastrophize experience more pain, feel more disabled by their pain, and suffer more psychological distress (Vlaeyen and Linton, 2000; Picavet et al., 2002). The results of the present study extend those findings by suggesting that decatastrophizing the consequences of the pain experience possibly constitutes an important therapy ingredient accounting for the variance in outcome. Catastrophizing appears to be a cognitive pain variable not only of importance in the development and chronification of pain, but also in the effective treatment of pain.

Some limitations of the present study have to be acknowledged. First, given the limited contact hours available for cognitive coping skills training ( $18 \mathrm{~h}$ ) in comparison to the contact hours with various professionals during the operant-behavior therapy program (132 h) it can be questioned whether the 
Spinhoven, P., Kuile, M. ter, Kole-Snijders, A.M.J., Hutten Mansfeld, M., Ouden, D.J. den, Vlaeyen, J.W.S.

Catastrophizing and internal pain control as mediators of outcome in the multidisciplinary treatment of chronic low back pain.

European Journal of Pain: 8, 2004, p. 211-219

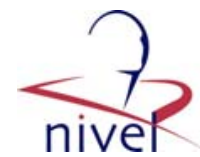

cognitive coping skills training was extensive enough to expect differential effects on pain coping and cognitions in comparison to the control condition. Although the supplemental cognitive coping skills training was focused on learning adaptive cognitive coping responses and relaxation, the comprehensive and interdisciplinary nature of the treatment, rather than specific components that are added to it, may have been the most important treatment factor. Second, the process measure analyzed in this study, the PCCL, was reconstructed on the basis of three other questionnaires (the PCL, CSQ, and MPLC). Therefore, it may not be warranted to assume that the PCCL as a separate instrument would have yielded the same study results as found with the PCCL as embedded in the PCL, CSQ, and MPLC. Third, patients who dropped out of treatment had significantly lower pretreatment scores for Catastrophizing than treatment completers. Moreover, in the present study patients with serious psychopathology were excluded. Taken together, these two findings may have affected the external validity of the present study results in the sense that foremost patients with on average moderate scores for Catastrophizing and psychopathology completed treatment. Most likely this has resulted in an underestimation of the association of changes in Catastrophizing with outcome because of restriction of range of scores on main variables under study. Future studies has to address the issue whether the cognitive mediation of outcome is independent of sample characteristics or is moderated by variables such as type of pain complaint or severity of psychopathology. Finally, the correlational nature of the data preclude definitive causal inferences. Clinical studies repeatedly assessing cognition and outcome over the course of treatment and more stringent experimental studies are needed to determine whether clinical interventions and experimental manipulations to change cognitions result in the expected outcome in terms of physical and psychological functioning.

In conclusion, a structured multidisciplinary treatment program for chronic pain modifies pain cognitions which may mediate emotional and behavioral adjustment to pain. Especially, a reduction of catastrophical cognitions about the consequences of pain may be an important mediator of treatment outcome. These findings are consistent with cognitive-behavioral conceptualizations of chronic pain which stress that catastrophizing plays a crucial role in the chronic pain experience and contributes to the variance in emotional and behavioral adjustment to chronic pain. The use of behavioral and cognitive interventions aimed at decreasing catastrophizing thoughts about the consequences of pain and promoting internal expectations of pain control possibly constitute an important avenue of change irrespective of the type of treatment.

\section{TABLES}

Table 1

Means and standard deviations on PCCL subscales at different time points between conditions

\begin{tabular}{|c|c|c|c|c|c|c|c|c|}
\hline \multirow[t]{2}{*}{ Variable } & \multicolumn{2}{|c|}{ Pretreatment $(N=130)$} & \multicolumn{2}{|c|}{ Posttreatment $(N=130)$} & \multicolumn{2}{|c|}{ Follow-up $(N=89)$} & \multirow{2}{*}{$\begin{array}{l}\text { Significant group } \\
\text { differences }^{\mathrm{a}}\end{array}$} & \multirow[t]{2}{*}{$p<b$} \\
\hline & $M$ & SD & $M$ & SD & $M$ & SD & & \\
\hline \multicolumn{9}{|c|}{ Catastrophizing (range: 12-72) } \\
\hline OPCO & 40.0 & 9.5 & 31.5 & 9.7 & 30.5 & 11.5 & a & \multirow[t]{3}{*}{0.01} \\
\hline OPDI & 41.3 & 8.2 & 32.1 & 8.8 & 33.4 & 9.8 & $\mathrm{~b}$ & \\
\hline WLC & 41.1 & 9.2 & 39.4 & 8.9 & $(-)$ & $(-)$ & $a, b$ & \\
\hline \multicolumn{9}{|c|}{ Pain Coping (range: 11-66) } \\
\hline OPCO & 41.1 & 7.8 & 42.7 & 8.8 & 40.9 & 9.2 & & \multirow[t]{3}{*}{$\mathrm{n} . \mathrm{s}$} \\
\hline OPDI & 37.5 & 6.9 & 38.6 & 7.8 & 38.4 & 7.7 & & \\
\hline WLC & 40.0 & 5.3 & 39.4 & 5.2 & $(-)$ & $(-)$ & & \\
\hline \multicolumn{9}{|c|}{ Internal Pain Control (range: 11-66) } \\
\hline OPCO & 35.9 & 6.4 & 42.3 & 9.1 & 38.4 & 9.7 & a & \multirow[t]{3}{*}{0.001} \\
\hline OPDI & 34.8 & 5.9 & 40.8 & 8.6 & 38.5 & 7.4 & $\mathrm{~b}$ & \\
\hline WLC & 38.0 & 6.2 & 37.9 & 7.1 & $(-)$ & $(-)$ & $\mathrm{a}, \mathrm{b}$ & \\
\hline \multicolumn{9}{|c|}{ External Pain Control (range: 8-48) } \\
\hline OPCO & 27.3 & 4.7 & 25.1 & 4.6 & 25.3 & 5.7 & a & \multirow[t]{3}{*}{0.01} \\
\hline OPDI & 25.5 & 5.6 & 23.1 & 4.6 & 24.1 & 5.2 & $\mathrm{~b}$ & \\
\hline WLC & 26.5 & 4.6 & 27.1 & 4.8 & $(-)$ & $(-)$ & $a, b$ & \\
\hline
\end{tabular}

Note. Sample sizes vary because of missing data; $\mathrm{PCCL}=$ Pain Coping and Cognition List; OPCO $=$ operant-behavioral treatment + cognitive coping skills treatment; OPDI = operant-behavioral treatment + group discussion; WLC $=$ waiting-list condition

${ }^{\text {a }}$ Groups that significantly differed are indicated by a common letter.

${ }^{\mathrm{b}}$ Overall $p$ value is provided for Group $\times$ Time interaction. 
Spinhoven, P., Kuile, M. ter, Kole-Snijders, A.M.J., Hutten Mansfeld, M., Ouden, D.J. den, Vlaeyen, J.W.S.

Catastrophizing and internal pain control as mediators of outcome in the multidisciplinary treatment of chronic low back pain.

European Journal of Pain: 8, 2004, p. 211-219

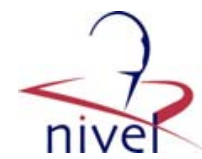

Table 2

Means and standard deviations on outcome measures at different time points between conditions

\begin{tabular}{|c|c|c|c|c|c|c|c|}
\hline \multirow[t]{2}{*}{ Variable } & \multicolumn{2}{|c|}{ Pretreatment $(N=130)$} & \multicolumn{2}{|c|}{ Posttreatment $(N=130)$} & \multicolumn{2}{|c|}{ Follow-up $(N=89)$} & \multirow[b]{2}{*}{$p<<^{\mathrm{a}}$} \\
\hline & $M$ & SD & M & SD & $M$ & SD & \\
\hline \multicolumn{8}{|l|}{ MPQ: PRI } \\
\hline Treatment & 23.7 & 10.0 & 21.6 & 11.5 & 24.0 & 12.1 & n.s. \\
\hline WLC & 24.3 & 9.7 & 23.1 & 9.1 & $(-)$ & $(-)$ & \\
\hline \multicolumn{8}{|l|}{ BDI } \\
\hline Treatment & 13.7 & 7.5 & 11.1 & 7.4 & 11.0 & 8.8 & .05 \\
\hline WLC & 14.0 & 6.7 & 14.6 & 10.4 & $(-)$ & $(-)$ & \\
\hline \multicolumn{8}{|l|}{ PBS } \\
\hline Treatment & 3.3 & 1.7 & 1.8 & 1.5 & 2.2 & 1.8 & .001 \\
\hline WLC & 3.4 & 1.6 & 2.9 & 1.9 & $(-)$ & $(-)$ & \\
\hline \multicolumn{8}{|l|}{ BAT } \\
\hline Treatment & .04 & 2.7 & 2.4 & 2.6 & 1.8 & 2.8 & .001 \\
\hline WLC & -.5 & 2.8 & -.6 & 3.0 & $(-)$ & $(-)$ & \\
\hline
\end{tabular}

Note. Sample sizes vary because of missing data; MPQ:PRI = McGill Pain Questionnaire:Pain Rating Index; BDI = Beck Depression Inventory; PBS = Pain Behavior Scale; BAT = Behavioral Approach Test; Treatment involved an operant-behavioral treatment plus cognitive coping skills training $(\mathrm{OPCO})$ or group discussion $(\mathrm{OPDI})$; WLC $=$ waiting-list condition.

${ }^{\text {a }}$ Overall $p$ value is provided for Group $\times$ Time interaction.

Table 3

Zero-order correlations with 95\%-confidence intervals among treatment, changes on outcome measures and changes on process measures $(N=130)$

\begin{tabular}{llllll}
\hline Variable & Treatment & rgs BDI & rgs PBS & rgs BAT & rgs MPQ:PRI \\
\hline $\begin{array}{l}\text { Treatment } \\
\text { (Yes =0; No }=1)\end{array}$ & $(-)$ & $.21^{*}(04 / 37)$ & $0.34^{* * *}(18 / 48)$ & $-.50^{* * *}(-62 /-36)$ & $.05(-12 / 22)$ \\
rgs PCCL:Cat & $0.36^{* * *}(20 / 50)$ & $.41^{* * *}(26 / 54)$ & $.45^{* * *}(30 / 58)$ & $-0.40^{* * *}(-53 /-24)$ & $.29^{* *}(12 / 44)$ \\
rgs PCCL:Int & $-0.34^{* * *}(-48 /-18)$ & $-0.27^{* *}(-42 /-10)$ & $-0.41^{* * *}(26 / 54)$ & $.33^{* * *}(17 / 47)$ & $-0.18^{*}(-34 / 01)$ \\
rgs PCCL:Ext & $0.33^{* * *}(17 / 47)$ & $0.27^{* *}(10 / 42)$ & $0.30^{* * *}(13 / 45)$ & $-0.32^{* * *}(-47 /-16)$ & $0.25^{* *}(08 / 40)$ \\
rgs PCCL:Cop & $-0.12(-28 / 05)$ & $-0.01(-18 / 16)$ & $-0.12(-29 / 05)$ & $0.10(-07 / 27)$ & $0.15(-02 / 31)$ \\
\hline
\end{tabular}

Note. Sample sizes vary because of missing data. $\mathrm{rgs}=$ residualized gain score; Numbers in parenthesis are $95 \%$-confidence intervals; $\mathrm{BDI}=\mathrm{Beck}$ Depression Inventory; PBS = Pain Behavior Scale; BAT = Behavioral Approach Test; MPQ:PRI = McGill Pain Questionnaire:Pain Rating Index; $\mathrm{PCCL}=$ Pain Coping Cognition List: Cat $=$ Catastrophizing; Int $=$ Internal Pain Control; Ext $=$ External Pain Control; Cop $=$ Pain Coping.

${ }^{*}<0.05$.

${ }^{* *}<0.01$.

${ }^{* * *}<0.001$

Table 4

Semi-partial correlations from hierarchical regressions of changes on outcome measures on treatment and changes on process measures $(N=130)$

\begin{tabular}{|c|c|c|c|c|}
\hline \multirow[t]{2}{*}{ Predictor } & \multirow[b]{2}{*}{ rgs BDI } & \multicolumn{2}{|l|}{ Criterion } & \multirow[b]{2}{*}{ rgs MPQ:PRI } \\
\hline & & rgs PBS & rgs BAT & \\
\hline Treatment $(\mathrm{Yes}=0 ; \mathrm{No}=1)$ & .02 & .13 & $-.34^{* * *}$ & -.10 \\
\hline rgs PCCL:Cat & $.27^{* *}$ & $.23^{* *}$ & $-.15^{*}$ & $.20^{*}$ \\
\hline rgs PCCL:Int & -.10 & $-.18^{*}$ & .04 & -.12 \\
\hline rgs PCCL:Ext & .07 & .05 & -.09 & .10 \\
\hline rgs PCCL:Cop & .08 & .02 & .01 & $.21^{*}$ \\
\hline Multiple $R^{2}$ & .19 & .28 & .32 & .16 \\
\hline
\end{tabular}

Note. Sample sizes vary because of missing data. $\mathrm{rgs}=$ residualized gain score; BDI = Beck Depression Inventory; PBS = Pain Behavior Scale; BAT = Behavioral Approach Test; MPQ:PRI = McGill Pain Questionnaire: Pain Rating Index; PCCL = Pain Coping Cognition List: Cat $=$ Catastrophizing; Int $=$ Internal Pain Control; Ext $=$ External Pain Control; Cop $=$ Pain Coping

$*<.05$.

$* *<.01$

$* * * .01$. 
Spinhoven, P., Kuile, M. ter, Kole-Snijders, A.M.J., Hutten Mansfeld, M., Ouden, D.J. den, Vlaeyen, J.W.S.

Catastrophizing and internal pain control as mediators of outcome in the multidisciplinary treatment of chronic low back pain.

European Journal of Pain: 8, 2004, p. 211-219

\section{REFERENCES}

1. Bandura A. Social learning theory. Englewood Cliffs, NJ: Prentice- Hall; 1977.

2. Baron RM, Kenny DA. The moderator-mediator variable distinction in social psychological research: conceptual, strategic, and statistical considerations. J Personal Soc Psychol 1986;51:1173-82.

3. Beck A, Rush AJ, Shaw BP, Emery G. Cognitive therapy of depression. New York: Guilford Press; 1979.

4. Engstrom D. Cognitive behavioral therapy methods in chronic pain treatments. In: Bonica JJ et al., editors. Advances in pain research and therapy. New York: Raven Press; 1983. p. 82938.

5. Fernandez E. A classification system of cognitive coping strategies for pain. Pain 1986;26:141-51.

6. Hathaway SR, McKinley JC. Minnesota multiphasic personality inventory. rev ed. New York: Psychological Corporation; 1967.

7. Jensen MP, Turner JA, Romano JM, Karoly P. Coping with chronic pain: a critical review of the literature. Pain 1991;47:249-83.

8. Jensen MP, Turner JA, Romano JM. Relationship of pain-specific beliefs to chronic pain adjustments. Pain 1994;57:301-9.

9. Jensen MP, Turner JA, Romano JM. Changes in beliefs, catastrophizing, and coping are associated with improvement in multidisciplinary pain treatment. J Consult Clin Psychol 2001;69:655-62.

10. Kole-Snijders AMJ, Vlaeyen JWS, Goossens MEJB, Rutten-van Molken MPMH, Heuts PHTG, Van BG, Van Eek H. Chronic low-back pain: what does cognitive coping skills training add to operant behavioral treatment. Results of a randomized clinical trial. J Consult Clin Psychol 1999;67:931-44.

11. Kole-Snijders AMJ, Vlaeyen JWS, Van Eek H, Schuerman JA, Groenman NH. Behavioral assessment of residual health behavior in chronic low back pain patients through the pain-rest contingency principle. Pain 1990;5:S394.

12. Lazarus RA, Folkman S. Stress, appraisal, and coping. New York: Springer; 1984.

13. Melzack R. The McGill Pain Questionnaire: major properties and scoring methods. Pain 1975;1:277-99.

14. Morley S, Eccleston C, Williams A. Systematic review and metaanalysis of randomized controlled trials of cognitive behaviour therapy and behaviour therapy for chronic pain in adults, excluding headache. Pain 1999;80:1-13.

15. Picavet HSJ, Vlaeyen JWS, Schouten JSAG. Pain catastrophizing and kinesiophobia: predictors of chronic low back pain. Am J Epidemiol 2002;156:1028-34.

16. Richards AH, Nepomuceno C, Riles M, Suer Z. Assessing pain behavior: the UAB Pain Behavior Scale. Pain 1982;12:393-8.

17. Rosenstiel AK, Keefe FJ. The use of coping strategies in chronic low back pain patients: relationship to patient characteristics and current adjustment. Pain 1983;17:33-44.

18. Spinhoven P, ter Kuile MM, Linssen ACG. Coping met Pijn Vragenlijst (CPV). Handleiding/experimentele versie. Lisse: Swets \& Zeitlinger; 1994.

19. Stomp-van den Berg SGM, Vlaeyen JWS, ter Kuile MM, Spinhoven P, Van BG, Kole-Snijders AMJ. Meetinstrumenten chronische pijn. Deel 2. Pijn Coping en Cognitie Lijst (PCCL). Maastricht: Pijn Kennis Centrum; 2001.

20. Ter Kuile MM, Linssen ACG, Spinhoven P. The development of the Multidimensional Locus of Pain Control Questionnaire (MLPC): factor structure, reliability, and validity. J Psychopathol Behav Assess 1993;15:387-404.

21. Turner JA, Chapman CR. Psychological interventions for chronic pain. II. A critical review: operant conditioning, hypnosis and cognitive-behavioral therapy. Pain 1982;12:23-46.

22. Vlaeyen JWS, Geurts SM, Kole-Snijders AMJ, Schuerman JA, Groenman JA, Van Eek NH. What do chronic pain patients think of their pain. Towards a pain cognition questionnaire. $\mathrm{Br} \mathrm{J}$ Clin Psychol 1990;28:383-94.

23. Vlaeyen JWS, Linton SJ. Fear-avoidance and its consequences in chronic musuloskeletal pain: a state of the art. Pain 2000;85:317-32. 